\title{
The Film Philadelphia As A Case Study Of Ethical Dilemmas In The Workplace
}

Carlos B. Gonzalez, California State Polytechnic University, Pomona Agustin F. Zarzosa, State University of New York, Purchase College

\begin{abstract}
In this paper we present the film Philadelphia as an exemplary text for teaching business ethics. For this purpose, we show students three scenes from the film and guide them as they engage in ethical reasoning. Through the exercise, students should: understand the nature of ethical dilemmas; understand a model for ethical decision-making and apply it to shed light on selected situations presented in the film; and lastly, understand ethical dimensions of discrimination. After engaging with the exercise, students should also develop a clear understanding of the difficulty of reaching ethical decisions in their professional careers. In addition, the exercise serves as an opportunity to discuss issues of HIV and AIDS in contemporary organizations.
\end{abstract}

Keywords: experiential learning, ethics, diversity, discrimination, HIV, AIDS

\section{INTRODUCTION}

1 $\mathrm{n}$ an age dominated by visual culture, management scholars have recognized the value of film as a teaching resource (e.g., Champoux, 1999, 2006; Comer, 2001; Czarniawska-Joerge \& Guillte, 1994; Huczynski \& Buchanan, 2004; Mallinger \& Rossy, 2003; McCambridge 2003). Following this pedagogical tradition, this article proposes the film Philadelphia (Saxon \& Demme, 1993) as an exemplary text to teach and discuss ethical dilemmas in the workplace. We focus our analysis on three scenes that dramatize ethical theories and concepts: the first scene offers an opportunity to discuss ethical dilemmas along with a model for ethical decision making; the second scene raises questions about the verifiability of ethical acts; lastly, the third scene presents an example of organizational storytelling regarding discrimination and its ethical dimensions.

Furthermore, the film introduces students to the issue of discrimination based on sexual orientation and HIV status at the workplace. We believe this to be an important subject. Issues of diversity and discrimination are keenly debated within the managerial literature. However, issues of HIV and AIDS seem to have been forgotten by management scholars. It seems as if the issue belonged to the 1980s and 1990s but is not an issue for the early twenty-first century. Obviously, we disagree, and through the film we want to develop a discussion with our students regarding HIV and AIDS at the workplace while discussing ethical dimensions of managerial decision making.

In the movie, Andrew Beckett (Tom Hanks), a successful lawyer, conceals his sexual orientation and HIV status from the senior partners at Wyant \& Wheeler, the law firm where he works. When he is promoted to "'Senior Associate," he is given a very important case. However, important documents regarding the case are misfiled at the same time that Kaposi's Sarcoma lesions begin to appear on his face. Because of the misfiling, Andrew is accused of incompetence and fired. Nevertheless, he suspects that he has been fired because of his HIV status and sexual orientation. Andrew hires Joe Miller (Denzel Washington), an African-American "ambulance-chaser" lawyer, to represent him in a wrongful termination lawsuit against Wyant \& Wheeler. The film centers on the trial and on the relationship that develops between Andrew and Joe. 


\section{THE EXERCISE:}

\section{Guidelines For Instructor}

If possible, we suggest students watch the movie in its entirety at home. However, this is not essential as long as the instructor provides background information about the movie and on each of the segments. Table One provides an example of guiding questions students can answer while they are watching the scenes.

Table 1

\section{Questions for Discussion:}

1. How would you describe the ethical dilemma confronted by the managers at the law firm?

2. Are the managers at Wyant \& Wheeler justified in firing Andrew? What set of criteria would you use to arrive at this decision?

3. How is the fact that Andrew concealed his illness relevant to the case?

4. Is Joe morally obliged to accept Andrew's case?

5. Why do you think that Joe finally accepts the case?

6. If you witnessed an instance of discrimination, would you intervene? What would inform your decision?

7. Are we ethically entitled to interpret the experience of others?

8. How does our interpretation alter the experience of others?

9. What are the consequences of believing or not believing these experiences?

Segment One: DVD Chapters 4 \& 5 (Start: 22:33 - Stop: 28:50).

Before watching the DVD clip instructors should read Cavanagh, Moberg, and Velasquez's (1981) model for ethical decision-making. The paper could be assigned for students to read or the instructor could briefly lecture on it. However, the model should be discussed before students watch the segment. That is, students should understand that their analysis of the film should be based on the framework provided by Cavanagh et al.

In the segment, a haggardly looking Andrew enters Joe Miller's office. After explaining that he has AIDS, Andrew tells Joe that he is seeking representation in a wrongful termination suit against his former employer, a case nine lawyers have already declined. Andrew recounts the events that led to his termination: He left a complaint that was due in court the following day on top of his desk. The following morning, the document disappeared along with all backup files in his computer. Mysteriously, the document reappeared a few minutes before the court's closing time. A flashback takes the audience to Wyant \& Wheeler, where the senior partners tell Andrew that he has an attitude problem and has become unreliable. For these reasons, they claim, his future in the firm is no longer secure. Back in Joe Miller's office, Joe is skeptical that Andrew has been sabotaged or that he has a case. Andrew tells Joe that he does in fact have a case, but that Joe does not want it for personal reasons; Joe agrees. The segment ends when Andrew leaves the office.

\section{Analysis:}

In the exercise we follow Rest's (1986) description of the ethical decision making process. For Rest, ethical decision-making involves four components - identifying an ethical dilemma; making a moral judgment; establishing moral intent; and engaging in moral action (O'Fallon \& Butterfield, 2005). This exercise provides a structured experience in which to guide students through the process described by Rest.

Accordingly, once students have watched the first segment, ask them if they recognize an ethical dilemma. The question to be discussed is whether the partners at Wyant \& Wheeler are confronted with an ethical question. 
An outstanding employee shows signs of AIDS: Should they fire him? Is this an ethical dilemma or not? At this moment it is important to provide a working definition of ethical dilemmas for students. That is, an ethical dilemma arises when two primary values conflict with each other and engaging in one action precludes another. This is a simple concept but one that many students fail to recognize. Also, when engaging in this discussion, it is necessary to create an environment where students feel comfortable with and capable of discussing highly controversial topics such as sexual orientation, HIV, and disability. The instructor should help students recognize the difficulty of identifying an ethical dilemma.

Besides been able to recognize ethical dilemmas, it is also important to provide students with a framework, a heuristic that will help them obtain a moral judgment. As O'Fallon \& Butterfield (2005) point out, there are hundreds of articles and models that attempt to provide such a judgment. We have chosen the model of Cavanagh et al (1981) due to its simplicity for an undergraduate class. Following their model, we can analyze this dilemma from three different ethical criterions: the utilitarian, rights, and justice models. We suggest instructors discuss all three concepts and write them down on the blackboard, incorporating students' answers as they provide suggestions to solve the ethical dilemma.

The utilitarian approach stresses the consequences of an action in obtaining the greatest good for the greatest amount of people. Accordingly, in determining how to resolve the ethical dilemma from a utilitarian standpoint, it is important to help students identify the common good for Wyant \& Wheeler's stakeholders. That is, it is important to identify the various stakeholders and how, in the aggregate, the firm must obtain an outcome that will advance the communal wellbeing. In our experience, students provide a wide range of answers. For example, students have argued that Andrew might infect other employees, thus presenting a health hazard. Other students have argued that keeping him in his position might increase the organization's health insurance costs. Within this rationale, it might be in the best interest of the organization to fire Andrew. Also, students mention the effects that firing Andrew might have on the morale of other employees. Anyone with a devastating disease could get fired.

However, when discussing the utilitarian approach, students sometimes go into the rights approach. It is easy to confuse them and the instructor should be very clear on the difference. The utilitarian approach focuses on the aggregate, on the group; the rights approach focuses on each individual or group that might be affected and the fundamental rights of each. Again the concept of stakeholders is important but the analysis is different. When considering the rights approach, instructors should focus on each individual or group in isolation, and identify the fundamental or natural rights of each. Accordingly, a decision is ethical as long as the fundamental rights of all affected people affected are protected: this approach requires weighing Andrew's rights against those of other employees, clients and managerial staff.

When analyzing the case, students have presented several answers. For instance, Andrew has the fundamental right to earn a dignified living until the day he dies; on the other hand, the health and safety of other employees and clients might be jeopardized by Andrew's presence at the office. Fellow employees and clients have the right to work in a hazard-free environment. Other students have mentioned their moral opposition to working with an openly gay man who is also HIV positive. These students believe they have the fundamental right to forbid behaviors they consider offensive.

Lastly, the justice approach (specifically, its procedural aspects in organizations) focuses on the fairness of procedures that determine a given ethical decision. An analysis based on the justice approach makes sure that each party affected by a managerial decision had a voice in presenting their views to the people making decisions. This includes presenting evidence and any kind of information they think necessary. From this perspective, as an organization, Wyant \& Wheeler must create processes that protect the interests of all parties involved. In this case, the managing partners made their decision through a process that thwarted Andrew's voice. Since the process did not provide Andrew a fair hearing, he was left with no option other than litigation.

After students have presented all their arguments, it is necessary to analyze them. That is, how is the information obtained useful in making an ethical decision? This should be the guiding question while addressing the class and trying to achieve an ethical decision. Many ethical concepts can be used for making the analysis. An 
example is Kant's Categorical Imperative, which stipulates that ethical propositions demand an action (Kant, 1785). However, according to this concept, ethical actions sometimes go against social custom. This is an important concept and based in reason. In order to perform this imperative, the individual must check their beliefs and opinions in order to find out what reason demands. One way to achieve this is through research and the scientific method. From within this purview it is necessary to analyze students' comments and figure out which arguments sustain themselves after scrutiny. For example, the risk of HIV infection at work, while not zero, is very low. Also, other arguments must be analyzed one by one against an objective measurement. This quest for information and research means that the individual must go beyond his/her personal values and find moral values dictated by reason. In other words, as Rest (1986) puts it, " The person must give priority to moral values above other personal values such that a decision is made to intend to do what is morally right, (p. 3)."

Summarizing, the process is as follows:

1. Explain the objectives to the class.

2. Explain the model of Cavanagh et al.

3. Show the DVD clip.

4. Lead the class in a discussion about ethical dilemmas.

5. Once the dilemma has been identified, discus the utilitarian, rights, and justice criterion for ethical decisionmaking, and write students' answers on the blackboard..

6. Help students summarize the information obtained and use it to make a decision.

7. (Optional) After showing the clip, ask students to join in small groups and provide a group answer to questions 1-3 in the questionnaire, please see Table One. After students have answered the questions, proceed with Step 4.

Segment Two: DVD Chapter 6 (Start: 33:05 - Stop: 39:49)

The second segment illustrates the connection between ethical concerns regarding diversity and issues of social justice, specifically, social oppression. In this scene, Joe Miller is at the same legal library where Andrew is researching his case. Joe witnesses a situation of apparent discrimination between Andrew and a librarian. After observing how Andrew is discriminated against at the library, Joe is confronted with an ethical dilemma: should he intervene on Andrew's behalf, or should he mind his own business? What set of forces would compel an individual to choose one course of action over the other? This is the question students should be answering while watching this vignette. The class should address issues about the verifiability of ethical acts; that is, understand our ability to know why we act ethically and establish if our acts are ethical or not. It is clear that Joe decides to intervene and to accept Andrew's case after witnessing how Andrew is discriminated against; however, it is unclear why he decides to intervene. Invoking an absolutist view of ethics such as Kant's Categorical Imperative, we might suggest that Joe intervenes because that is the right thing to do despite his personal beliefs. Invoking theories of social justice, we might suggest that Joe intervenes by relating the oppression that as an African-American man he might have suffered to the oppression that Andrew is suffering. This is also consistent with Rest's argument; for him, once a decision is made and reason mandates that an ethical action is imperative, then the person must have the perseverance to continue his/her actions. Thus, students must ask themselves: what would compel a person to act ethically? Joe Miller could have hidden behind his books and no action would have been required but he chose not to hide. Why?

Segment Three: DVD Chapter 13 (Start: 56:50 - Stop: 59:16)

Lastly, the third segment illustrates how testimonials of discrimination are fraught with ethical questions. Unlike the second segment, in which Joe witnesses an instance of discrimination, this scene presents Anthea's (Anna Deveare Smith) account of discrimination and her interpretation of the events. Tellingly, the defense lawyer questions not the events themselves, but rather Anthea's interpretation of these events. Therefore, the scene presents the following question: To what extent are we free to give a different interpretation to the experience of others? The defense lawyer's interpretation of Anthea's experience as a "misunderstanding" reaches beyond the realm of interpretation and discounts Anthea's experience. Such an interpretation implies that Anthea does not have the ability to assess her own experience. To the extent that interpretation is an inherent component of experience, 
interpretation is not ethically neutral. Furthermore, social power plays an important role in this process of reinterpretation; in certain circumstances, social power may be exercised by re-interpreting the experience of others. Therefore, re-interpreting experience can further victimize a person. Thus, it is important to ask students if there are ethical ramifications to organizational storytelling regarding discrimination. If a person narrates their experience about discrimination, the listener has two options: to believe it or not to believe it. However, in either case, there are consequences for the person whose narrative has been exposed. Do those consequences belong to the realm of ethics? It is our belief that they do.

Additional Comments: After discussing the ethical dimensions of HIV/AIDS, it is important to provide students with up-to-date information. At the time the film was released (1993), an AIDS diagnostic almost equaled a certain death. This situation, however, changed in the late 1990s with the emergence of HIV combination therapy, which turned HIV infection into a manageable condition. As a result of this therapy, most HIV positive people no longer develop full blown AIDS. However, AIDS is not quite a thing of the past: the long-term effects of using HIV medication can be hazardous; although rare, a few strains of HIV are resistant to available medication; and scientists have been unable to develop a vaccine. Moreover, according to the Centers for Disease Control and Prevention (CDC), the face of HIV infection is changing: in the early years of the $21^{\text {st }}$ century, the number of infected women (particularly, women of color) will surpass the number of infected men worldwide. In the United States, approximately 40,000 people become infected with the virus every year and, despite the new therapies, 16,316 people died from AIDS in 2005 (US CDC Website, 2007). By 2003, an estimated 1,039,000 to 1,185,000 persons in the United States were living with HIV/AIDS. Consequently, the issue of HIV infection and AIDS remains relevant in contemporary organizations.

\section{AUTHOR INFORMATION}

Carlos B. González is an organizational behavior scholar and consultant in both his native Puerto Rico and the U.S. Currently, Dr. González is faculty at California State Polytechnic University, Pomona. He earned his doctorate in Management from the University of Massachusetts at Amherst. His research interests include diversity and crosscultural management.

Agustin F. Zarzosa is an Assistant Professor of Film Studies at the State University of New York, Purchase College. Dr. Zarzosa obtained his doctorate from the University of California, Los Angeles. His research interests include philosophy as it relates to film analysis and the study of melodrama as a form of film narrative.

\section{REFERENCES}

1. Cavanagh, G.F., Moberg, D.J., \& Velasquez, M. (1981). The Ethics of Organizational Politics. The Academy of Management Review, 6(3), 363.

2. Champoux, J.E. (2006). At the Cinema: Aspiring to a Higher Ethical Standard. Academy of Management Learning and Education, 5(3), 386-390.

3. Champoux, J.E. (1999). Film as a Teaching Resource. Journal of Management Inquiry, 8(2), 206-217.

4. $\quad$ Comer, D.R. (2001). Not Just a Mickey Mouse Experience: Using Disney's The Lion King to Teach Leadership. Journal of Management Education, 25(4), 430-435.

5. Czarniawska-Joerges, B., \& Guillet de Monthoux, P. (1994). Good novels: better management: Reading organizational realities in fiction. Switzerland: Harwood Academic.

6. Huczynski, A., \& Buchanan, D. (2004) Theory from Fiction: A Narrative Process Perspective on the Pedagogical Use of Film. Journal of Management Education, 28(0), 707 -726.

7. Kant, I. (1785). Groundwork of the metaphysic of morals. London, Hutchinson University Library [1948]

8. Mallinger, M., \& Rossy, G. (2003). Film as a Lens for Teaching Culture: Balancing Concepts, Ambiguity, and, Paradox 27(5), 608-624.

9. McCambridge, J. (2003). 12 Angry Men: A Study in Dialogue. Journal of Management Education, 27(3), 384-401.

10. O'Fallon, M.J., \& Butterfield, K.D. (2005). A review of The Empirical Ethical Decision-Making Literature: 1996-2003. Journal of Business Ethics, 59, 375-413. 
11. Rest. J.R. (1986). Moral development: Advances in Research and Theory. Praeger: New York.

12. Saxon, E. (Producer), \& Demme, J. (Producer/Director). (1993) Philadelphia [Motion Picture]. United States: TriStar Pictures.

13. United States Centers for Disease Control (2007) A Glance at the HIV/AIDS Epidemic. Retrieved July, 23, 2007 from http://www.cdc.gov/hiv/resources/factsheets/At-A-Glance.htm

\section{NOTES}

